\title{
Diretrizes no tratamento das metástases epidurais da coluna vertebral. Atualização
}

\author{
Jefferson Walter Daniel', José Carlos Esteves Veiga² \\ Disciplina de Neurocirurgia do Departamento de Cirurgia da Faculdade de Ciências \\ Médicas da Santa Casa de São Paulo. São Paulo, SP, Brasil
}

\section{RESUMO}

Objetivo: Atualizar conceitos e recomendar condutas da prática médica nos aspectos de prognóstico, diagnóstico e tratamento das metástases epidurais da coluna vertebral. Método: O período de apuração das publicações situou-se entre janeiro de 1990 a janeiro de 2006, incluídas as referências relevantes prévias. A ausência de evidências de valor científico para determinar padrões ou diretrizes de conduta em temas médicos que geram incertezas da prática, permite usar do termo diretrizes para todas as recomendações. Resultados: A modalidade de tratamento a ser escolhido depende da análise dos fatores preditivos de prognóstico, tais como: o estado clínico do doente; a possibilidade de resgatar ou manter a capacidade de deambulação; grau de disseminação e transmissão da neoplasia primária. As informações obtidas com o diagnóstico de imagem da ressonância magnética efetuada em toda a extensão da coluna vertebral e o complemento das imagens ósseas pertinentes da tomografia axial computadorizada são necessárias na escolha e implementação do tratamento escolhido. O tratamento cirúrgico inclui a descompressão circunferencial da medula espinhal, a reconstrução do corpo vertebral e a estabilização segmentar da coluna vertebral. Conclusões: As recomendações conferem eficácia e eficiência nas condutas médicas. O prognóstico depende dos fatores preditivos de sobrevivência. Os exames complementares de imagem auxiliam no estadiamento e planejamento do tratamento. A modalidade de tratamento escolhida depende da previsão de sobrevivência e da capacidade de deambulação do doente.

\section{PALAVRAS-CHAVE}

Neoplasias da coluna vertebral. Metástase neoplásica. Diretrizes para a prática clínica.

\section{ABSTRACT}

Guidelines for treatment of epidural spinal metastases.

Objective: Bring up-to-date concepts and conduct practice parameters recomendations concerning aspects in prognosis, diagnosis and treatment of spinal epidural metastases. Method: Pertinent publications between January, 1990 and January, 2006, including previous relevant medical articles were reviewed. The absence of scientific value for evidence to determine conduct standards or guidelines in uncertain medical practice allows to use as guideline all recomendations. Results: The choice of a treatment modality depends on predictive prognosis factors, such as: patient's clinical state; preservation or salvage of walking capabilty; primary cancer spreading and transmission grade. Diagnostic information obtained by magnetic ressonance imaging of the spinal column complemented by pertinent computorized axial tomography bone images are necessary to choose and implement the treatment modality. Surgical treatment includes: circumferential spinal cord decompression; vertebral body reconstruction; segmental vertebral column stabilization. Conclusions: Recommendations bestow efficacy and efficiency of medical conducts. Complementary imaging studies are useful to determine the treatment, staging and planning. Treatment modality to be chosen depends on the patients'survival expectancy and their capability to walk.

\section{KEY WORDS}

Spinal neoplasmas. Neoplasma metastases. Practice guidelines.

1 Professor Instrutor da Disciplina de Neurocirurgia do Departamento de Cirurgia da Faculdade de Ciências Médicas da Santa Casa de São Paulo. Médico Assistente do Serviço de Neurocirurgia da Santa Casa de Misericórdia de São Paulo, SP.

2 Doutor e Professor Adjunto da Disciplina de Neurocirurgia do Departamento de Cirurgia da Faculdade de Ciências Médicas da Santa Casa de São Paulo, SP. Chefe do Serviço de Neurocirurgia dos Hospitais da Santa Casa de Misericórdia de São Paulo, SP. 


\section{Introdução}

Medicina baseada em evidências é um paradigma da medicina em situações que geram incertezas quanto aos aspectos de diagnóstico, prognóstico e manejo terapêutico das doenças. Os quatro princípios fundamentais para estruturar a medicina baseada em evidências são: a identificação da questão clínica que suscita dúvida; a realização de revisões sistemáticas de publicações científicas contemporâneas; a análise crítica das evidências encontradas nos artigos; e a ação de implementar, na prática clínica, a decisão validada pelas revisões sistemáticas. Os objetivos são a efetividade e a eficiência nas condutas médicas ${ }^{37}$.

A metodologia para o desenvolvimento de diretrizes segue critérios científicos rígidos nos conceitos elaborados, seguindo as orientações do Institute of Medicine Committee to Advise the Public Health Service on Clinical Practice Guidelines. A elaboração da evidência difere nos quesitos de diagnóstico, acesso clínico, prognóstico e terapêutica.

$\mathrm{O}$ conceito de relacionar as evidências às recomendações classifica os trabalhos da literatura por valor científico em classes de orientações. O mais elevado nível de evidência é classificado em "Classe I", denominado de "padrões de prática" ou do inglês, standards, indicando alto grau de certeza clínica. Evidência "Classe II", apóia recomendações denominadas de "diretrizes", ou guidelines, refletindo grau de moderada certeza clínica. Evidências que geram dúvidas nos resultados obtidos são categorizadas em "Classe III", denominadas de "opções", ou options e, determinam as incertezas clínicas na prática médica.

O termo geral usado para todas as recomendações é "parâmetros da prática", ou practice parameters. Existem poucos padrões de prática na medicina, e o termo com maior freqüência usado para descrever todas as recomendações é de diretrizes ${ }^{21}$.

Em vista da ausência de padrões de prática para diagnóstico, prognóstico e manejo terapêutico relativo ao tópico das metástases epidurais da coluna vertebral com compressão da medula e/ou da cauda eqüina, as recomendações dos parâmetros de prática estabelecidas são denominados de diretrizes.

O objetivo desta publicação é a atualização de conceitos e recomendações dos parâmetros sobre aspectos clínicos, diagnósticos, prognósticos e tratamento das metástases epidurais da coluna vertebral com compressão da medula e/ou da cauda eqüina.

\section{Material e método}

A pesquisa bibliográfica das publicações pertinentes ao assunto foi efetuada com o auxílio dos profissionais da área de pesquisa da Biblioteca da Faculdade de Ciências Médicas da Santa Casa de São Paulo, em fevereiro de 2006, através da busca de informações no Medline, com as palavras-chave spinal column metastases, guidelines for spinal metastases, treatment in spinal metastases, no período de janeiro de 1990 a janeiro de 2006. Referências de relevância não compreendidas no período de pesquisa também foram acessadas.

A análise crítica das evidências apuradas em publicações científicas contemporâneas relativas ao assunto identificou as questões de controvérsia e, com a proposta de implementar as decisões validadas propõe recomendações de eficiência e efetividade nas condutas médicas. Os principais tópicos apurados são expostos a seguir.

\section{Parâmetros da prática clínica e do prognóstico}

\section{Epidemiologia}

A coluna vertebral é o local do esqueleto de acometimento mais freqüente na doença metastática, envolvida em aproximadamente $40 \%$ dos doentes que falecem de câncer ${ }^{9}$. A histologia da neoplasia primária é fator predisponente quanto à possibilidade de ocorrer metástases para a coluna vertebral e compressão secundária do tecido nervoso. Neoplasias da próstata, das mamas e dos pulmões constituem $45 \%$ a $61 \%$ das compressões espinhais epidurais; linfoma não-Hodgkin, mieloma múltiplo e neoplasia dos rins contribuem cada um com $5 \%$ a $10 \%$; câncer colo-retal, neoplasia primária de origem não determinada e os sarcomas constituem o restante. Na população pediátrica, sarcomas (especialmente o tumor de Ewing), neuroblastoma, tumores renais e a doença de Hodgkin são as causas mais freqüentes de compressão epidural medular e/ou da cauda eqüina ${ }^{39}$, porém $\operatorname{raros}^{45}$. A probabilidade cumulativa de haver pelo menos um episódio de compressão medular e/ou da cauda eqüina nos cinco anos que precedem o falecimento do doente com câncer é de $2,5 \%{ }^{35}$. A faixa etária de maior incidência dos tumores vertebrais ocorre entre a quinta e sétima décadas de vida, sendo $70 \%$ a possibilidade de se tratar de tumores malignos. Em geral, o implante neoplásico inicial situa-se na região póstero-lateral do corpo da vértebra ${ }^{51}$.

\section{Fisiopatogenia}

Os tumores vertebrais são classificados em benignos e malignos e, estes últimos, em primários e 
secundários ${ }^{51}$. As metástases são responsáveis por aproximadamente $55 \%$ dos tumores raquimedulares ${ }^{51}$. Cerca de $98 \%$ das metástases são extradurais devido à proteção relativa da dura-máter. Metástases intradurais, situadas nas regiões extra e intramedular, originam-se de implantes por disseminação liquórica das neoplasias intracranianas primárias ou metastáticas ${ }^{15}$.

As metástases sintomáticas são localizadas em $70 \%$ dos casos na coluna torácica, $20 \%$ na região lombossacra, $10 \%$ no segmento cervical e são múltilplas em $17 \%$ a $30 \%$ dos doentes ${ }^{9,27}$. Os implantes neoplásicos iniciais ocorrem em $85 \%$ dos casos nas vértebras, de $10 \%$ a $15 \%$ nos espaços paravertebrais com extensão direta do crescimento para o interior do canal vertebral e raramente no espaço epidural ${ }^{9,27}$ (figura $1-\mathrm{A}, \mathrm{B}, \mathrm{C}$ ).

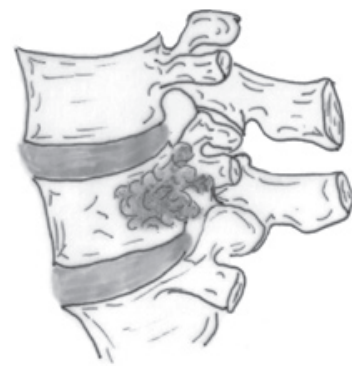

Figura 1A-Implante da neoplasia via hematogênica, situada na região póstero-lateral do corpo vertebral.

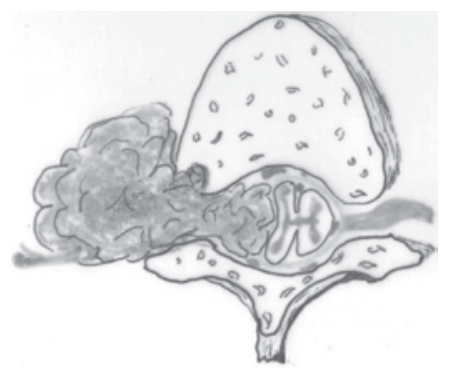

Figura $1 B$ - Extensão da neoplasia por contigüidade do crescimento para o interior do canal vertebral através do forâmen intervertebral.

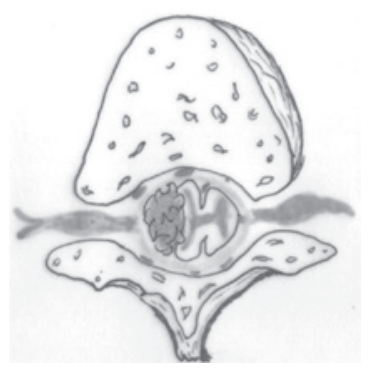

Figura 1C-Implante intradural e extramedular da metástase por disseminação através do líquido cefalorraquiano de neoplasia primária situada no compartimento intracraniano.
Os motivos de os implantes metastáticos iniciais serem mais freqüentes no corpo vertebral são: maior massa óssea e vascularização em relação aos elementos ósseos posteriores da vértebra; o suprimento vascular situa-se na região posterior e lateral do corpo vertebral, local anatômico do implante metastático inicial ${ }^{39}$ (figura 2).
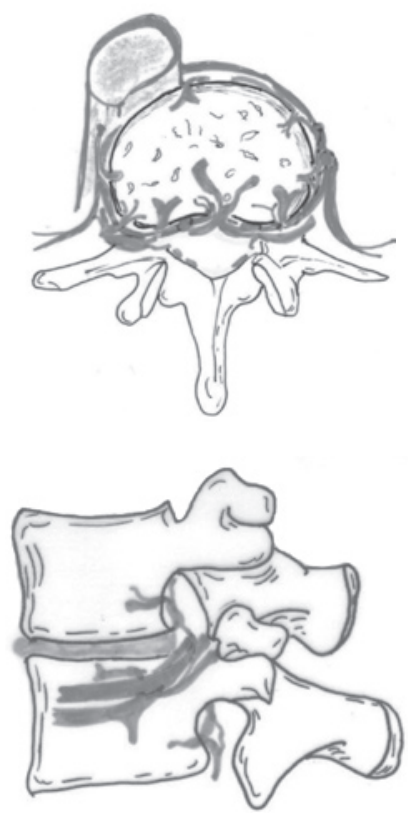

Figura 2 - Os ramos arteriais da dura-máter e do corpo vertebral $e$ as veias vertebrais do plexo venoso epidural adentram o canal vertebral através dos forâmens intervertebrais (aspectos anatômicos das vértebras nos planos axial e sagital).

A via hematogênica é a forma mais freqüente da transmissão das células neoplásicas e, geralmente, através do plexo venoso vertebral de Batson, o qual recebe a drenagem do sangue venoso das vísceras torácicas, abdominais e pélvicas por ocasião do aumento da pressão intracavitária, com fluxo retrógrado através de veias desprovidas de valvas ${ }^{9}$. Outras duas formas de transmissão são a extensão direta da neoplasia para o espaço epidural e por meio de êmbolos arteriais para as regiões corticais das vértebras ${ }^{15}$.

A lesão da medula espinhal é secundária à compressão direta por fragmentos ósseos deslocados através da ação osteoclástica da neoplasia e da massa tumoral, ocasionando congestão venosa, hipóxia, isquemia, edema e infarto medular segmentar, sendo definitivas as seqüelas neurológicas quando não tratadas².

A sintomatologia inicia-se após ruptura da camada cortical do corpo vertebral e extravasamento da neoplasia, com conseqüente invasão dos tecidos paravertebrais, compressão medular e dos nervos espinhais, e fraturas patológicas com instabilidade vertebral ${ }^{23}$. 


\section{Escolha do tratamento}

Fatores prognósticos de sobrevivência: o período mínimo de três a seis meses de expectativa de sobrevivência é proposto como consenso para justificar o tratamento cirúrgico paliativo. As opções do tratamento são determinadas após a análise da morbidade e riscos inerentes ao tratamento cirúrgico versus os possíveis benefícios oferecidos quanto à sobrevivência e qualidade de vida ${ }^{18,20}$. As vias de abordagem anterior e circunferencial da coluna vertebral são reservadas para os doentes com condições clínicas favoráveis. Procedimentos cirúrgicos de abordagens posteriores, que incluem a descompressão incompleta da medula espinhal da neoplasia, estabilização posterior e reconstrução parcial do corpo vertebral, são justificados em doentes com condições clínicas desfavoráveis ${ }^{10}$.

$\mathrm{O}$ indicador prognóstico mais importante é a biologia da neoplasia, a qual inclui sua histologia, sensibilidade à radioterapia e resposta a dexametasona e, os indicadores secundários, o estado neurológico prévio ao tratamento, a localização da neoplasia em relação ao canal vertebral e o estado clínico geral do doente ${ }^{6,49}$.

A capacidade de deambular previamente ao tratamento indica sobrevivência de melhor qualidade e por período maior ${ }^{2,49}$, sendo esse indicador o mais usado na expressão dos resultados do tratamento das metástases epidurais com compressão medular ${ }^{30}$. Os graus de "sucesso" e de "resgate" neurológico dos tratamentos para as metástases espinhais são definidos como a capacidade de manter a função de deambulação e readquirir a deambulação assistida ou não assistida, respectivamente ${ }^{28,30}$. Deficiência neurológica rapidamente progressiva em período inferior a 24 horas é indicador de prognóstico não favorável, com a possibilidade de paraplegia permanente em $28 \%$ a $35 \%$ dos casos. Em comparação, quando a deficiência neurológica é de evolução lenta, existe a possibilidade de $60 \%$ a $76 \%$ de haver melhora ou recuperação da capacidade de deambular ${ }^{15}$.

Os fatores de risco de complicações após o tratamento cirúrgico são: idade superior a 65 anos; déficit motor; radioterapia e/ou quimioterapias prévias. Cada fator duplica o risco, mesmo que ocorra isoladamente ${ }^{52}$. O prognóstico é sombrio e a sobrevivência após um ano do diagnóstico é de aproximadamente $35 \%{ }^{27}$.

A escolha da modalidade de tratamento - cirúrgico, radioterapia e/ou quimioterapia, associação da cirurgia à radioterapia e/ou à quimioterapia, apenas medidas de apoio clínico -, não segue recomendação de tratamento padrão (standard), existindo diretrizes (guidelines) em situações específicas de instabilidade e déficit neurológico incompleto e progressivo e, opções (options) relacionadas com a radioterapia como única modalidade de tratamento ${ }^{44}$.
A análise dos fatores prognósticos na seleção do candidato para o tratamento é individualizada e, para esse fim, são úteis os sistemas de classificações com escalas de graduações de comprometimento clínico e neurológico. Esses fatores são: histologia da neoplasia, o mais importante; duas ou mais metástases na coluna vertebral; estado neurológico prévio a cirurgia; presença de metástases extra-espinhais ${ }^{30}$; estado clínico geral ${ }^{34}$.

Os aspectos histológicos, clínicos e anatômicos determinantes da sobrevivência são demonstrados no quadro 1 .

Quadro 1
Indicadores prognósticos de sobrevivência da doença
metastática com envolvimento da coluna vertebral ${ }^{6,49}$

Sistemas de classificação quanto à decisão de tratamento das metástases da coluna vertebral: 0 sistema de classificação para o tratamento das metástases da coluna vertebral descrito por Harrington, em 1986, relaciona o grau de destruição óssea vertebral ao grau de comprometimento neurológico do doente, determinando a estratégia do tratamento cirúrgico ou não cirúrgico ${ }^{23}$.

Os sistemas com maior freqüência citados e usados como diretrizes na escolha do tratamento das metástases espinhais são de Tokuhashi e col. ${ }^{54,55} \mathrm{e}$ Tomita e col. ${ }^{56,57}$. A análise estatística de sobrevivência multivariável é considerada um refinamento da interpretação de dados, mas não é aceita de maneira universal ${ }^{17,25,40,50,52}$.

A seguir, os métodos são sumariados. Os sistema de pontuação para a avaliação do prognóstico dos tumores metastáticos espinhais proposto por Tokuhashi e col. ${ }^{54,55}$ tem o objetivo de determinar o prognóstico do doente com doença metastática e a estratégia adequada para o tratamento. É útil como indicador prognóstico em qualquer modalidade de tratamento e tipo histológico de tumor.

O sistema de pontuação prévio, de $1990^{54}$, foi revisado pelo mesmo autor e aplicado também para os doentes de tratamento não cirúrgico ${ }^{55}$. As diferenças das escalas consistem nos parâmetros de pontuação do tipo histológico das neoplasias, aumentando os possíveis somatórios dos pontos, de 12 do trabalho original para 15.

Prioridade para o período de sobrevivência é o parâmetro de escolha dos métodos cirúrgicos para o tratamento. Em doentes com pontuações inferiores a 8, tratamentos conservadores ou paliativos são selecionados (período de sobrevivência menor do que 6 meses). Pontuações de 9 a 11, raramente indicam métodos cirúrgicos radicais havendo como opções métodos paliativos de exérese do tumor, em lesões únicas e sem metástases 
para os órgãos internos principais (sobrevivência de 6 a 11 meses). Procedimentos cirúrgicos de exérese radical da neoplasia são selecionados em doentes com pontuações de 12 a 15 (sobrevivência superior a 12 meses). Nos doentes com múltiplas metástases, o tratamento conservador é a prioridade.

Está exposto no quadro 2 o sistema de avaliação proposto por Tokuhashi e col. ${ }^{55}$.

\begin{tabular}{|c|c|}
\hline \multicolumn{2}{|l|}{$\begin{array}{c}\text { Quadro } 2 \\
\text { Sistema de avaliação revisado para o prognóstico } \\
\text { dos tumores metastáticos espinhais }{ }^{55}\end{array}$} \\
\hline Parâmetros de pontuação & Pontos \\
\hline \multicolumn{2}{|l|}{ Condição geral (estado do desempenho de Karnofsky) } \\
\hline Ruim $(10 \%-40 \%)$ & 0 \\
\hline Moderado $(50 \%-70 \%)$ & 1 \\
\hline $\operatorname{Bom}(80 \%-100 \%)$ & 2 \\
\hline \multicolumn{2}{|l|}{ Número de focos de metástases ósseas extra-espinhais } \\
\hline$\geq 3$ & 0 \\
\hline$=2$ & 1 \\
\hline$=1$ & 2 \\
\hline \multicolumn{2}{|l|}{ Número de metástases nos corpos vertebrais } \\
\hline$\geq 3$ & 0 \\
\hline$=2$ & 1 \\
\hline$=1$ & 2 \\
\hline \multicolumn{2}{|l|}{ Metástase para os órgãos internos principais } \\
\hline Não passíveis de exérese cirúrgica & 0 \\
\hline Passíveis de exérese cirúrgica & 1 \\
\hline Ausência de metástases & 2 \\
\hline \multicolumn{2}{|l|}{ Local primário do câncer } \\
\hline Pulmão, osteosarcoma, estômago, bexiga, esôfago, pâncreas & 0 \\
\hline Fígado, vesícula, não determinado; & 1 \\
\hline Outros & 2 \\
\hline Rim, útero & 3 \\
\hline Reto & 4 \\
\hline Tireóide, mama, próstata. & 5 \\
\hline \multicolumn{2}{|l|}{ Déficit neurológico } \\
\hline Completo (Frankel A, B) & 1 \\
\hline Incompleto (Frankel C,D) & 2 \\
\hline Ausente (Frankel E) & 3 \\
\hline
\end{tabular}

O critério para a previsão do prognóstico de sobrevivência baseia-se no total de pontos obtidos no quadro 2 . Pontuação de 0-8: inferior a 6 meses; 9-11: 6 a 11 meses; 12-15: superior a 12 meses.

Estratégia cirúrgica para o tratamento de metástases espinhais proposto por Tomita e col. ${ }^{\mathbf{5 6}, 57}$ : esses autores propõem determinar estratégias de cirurgias para o tratamento das metástases espinhais associados a um sistema de pontuação para indicar o prognóstico. Baseado no número de pontos obtidos, a estratégia cirúrgica é escolhida. Os autores atribuem pontos para três indicadores prognósticos: grau de malignidade da neoplasia primária; metástases viscerais a órgãos vitais; metástases ósseas, inclusive vertebrais. O estado do desempenho clínico não especificado como fator prognóstico é presumido com a presença ou a ausência de metástases para os órgãos internos vitais. A classificação cirúrgica para os tumores espinhais separa-os em três grupos, com referência anatômica às vértebras: intravertebral ou intracompartimental; extravertebral ou extracompartimental; múltiplo. Ainda, esses três grupos são subdivididos em sete tipos, conforme a localização da neoplasia nas vértebras (figura 3).

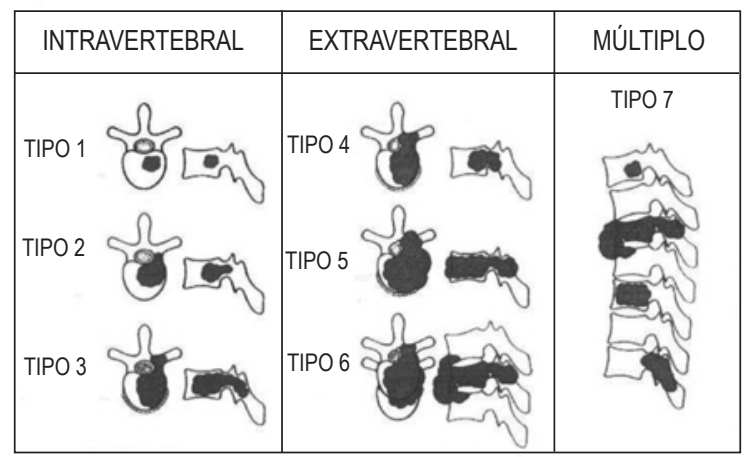

Figura 3 (modificado de Tomita e col. ${ }^{56,57}$ ) - Diagrama esquemático da classificação cirúrgica dos tumores espinhais.

A estratégia para a escolha da modalidade da cirurgia para as metástases espinhais é baseada nos objetivos do tratamento, os quais são determinadas com outro sistema de pontuação (Quadros 3 e 4) e relacionadas com a expectativa da sobrevivência do doente.

\begin{tabular}{|c|c|c|c|}
\hline \multicolumn{4}{|c|}{$\begin{array}{c}\text { Quadro } 3 \\
\text { Sistema de pontuação com os fatores prognósticos: tumor } \\
\text { primário, metástases viscerais e metástases ósseas }{ }^{56,57}\end{array}$} \\
\hline Pontos & $\begin{array}{l}\text { Tumor } \\
\text { primário }\end{array}$ & $\begin{array}{l}\text { Metástases } \\
\text { viscerais }\end{array}$ & $\begin{array}{l}\text { Metástases } \\
\text { ósseas }\end{array}$ \\
\hline 1 & $\begin{array}{l}\text { Crescimento } \\
\text { lento }\end{array}$ & Ausente & $\begin{array}{l}\text { Solitário ou } \\
\text { isolado }\end{array}$ \\
\hline 2 & $\begin{array}{l}\text { Crescimento } \\
\text { moderado }\end{array}$ & Tratável & Múltiplo \\
\hline 4 & $\begin{array}{l}\text { Crescimento } \\
\text { rápido }\end{array}$ & Não tratável & $\begin{array}{l}\text { Ausente ou } \\
\text { ignorado }\end{array}$ \\
\hline \multicolumn{4}{|c|}{$\begin{array}{c}\text { Quadro } 4 \\
\text { Sistema de pontuação prognóstica relacionado com o } \\
\text { objetivo do tratamento e estratégia cirúrgica }{ }^{56,57}\end{array}$} \\
\hline $\begin{array}{l}\text { Pontos } \\
\text { prognósticos }\end{array}$ & \multicolumn{2}{|c|}{$\begin{array}{l}\text { Objetivo do } \\
\text { tratamento }\end{array}$} & Estratégia cirúrgica \\
\hline 2 e 3 & \multicolumn{2}{|c|}{$\begin{array}{l}\text { Controle por } \\
\text { período longo }\end{array}$} & $\begin{array}{l}\text { Exérese ampla } \\
\text { ou marginal }\end{array}$ \\
\hline 4 e 5 & \multicolumn{2}{|c|}{$\begin{array}{l}\text { Controle por } \\
\text { período médio }\end{array}$} & $\begin{array}{c}\text { Exérese marginal } \\
\text { ou intralesional }\end{array}$ \\
\hline 6 e 7 & \multicolumn{2}{|c|}{$\begin{array}{l}\text { Medidas paliativas } \\
\text { por período curto }\end{array}$} & Cirurgia paliativa \\
\hline 8,9 e 10 & \multicolumn{2}{|c|}{ Cuidados terminais } & Tratamento de suporte \\
\hline
\end{tabular}

Nos doentes com pontuação de 2 a 3, o objetivo do tratamento é o controle por período prolongado da doença, com cirurgia radical incluindo amplas margens no local da neoplasia. Indicado quando a expectativa 
de sobrevivência é superior a dois anos. Pontuação de 4 a 5 indica cirurgia para o controle por período médio da doença, com a escolha de exérese intratumoral da neoplasia e, quando possível, exérese marginal. Quando o período de sobrevivência é de aproximadamente doze meses, indicado por pontuação de 6 a 7, cirurgia paliativa é a escolhida, visando descompressão da medula espinhal e estabilização da coluna vertebral. Pontuação prognóstica de 8 a 10 indica medidas de suporte clínico, não sendo proposto o tratamento cirúrgico.

Análise estatística de sobrevivência multivariável ${ }^{40}$ : Objetivo - padronização de dados variáveis entre séries de resultados de tratamentos para metástases da coluna vertebral para a comparação e seguimento do período da capacidade de deambular e a sobrevivência dos doentes. Método - Os valores prognósticos de variáveis independentes são analisados a fim de constituir escala ou modelo de pontuação. Os dados variáveis aplicados, entre outros possíveis, são: tipo do tumor, sexo, idade, capacidade de deambular, força muscular, continência dos esfíncteres, evolução dos sintomas de dor e alterações sensitivas, exames de imagem, período de diagnóstico até a realização da cirurgia, modalidade de cirurgia, terapia complementar. Os modelos de análises estatísticas de dados multivariáveis para a determinação do prognóstico são a análise de Kaplan-Meier para estimar as distribuições entre o evento e o período de seguimento após o tratamento e o modelo Cox que relaciona a sobrevivência entre os vários tipos histológicos de neoplasias.

\section{Escalas de graduações clínicas e terminologia}

Dados clínicos devem ser registrados de maneira uniforme nas avaliações clínicas e neurológicas prévias e posteriores ao tratamento, com a finalidade de padronizar a terminologia ${ }^{55}$. As definições, o método do exame neurológico, índices para os registros das avaliações da sensibilidade e motricidade, síndromes neurológicas são descritas na publicação "Padrões Internacionais para a Classificação Neurológica e Funcional de Lesões na Medula Espinal" "s, opção para terminologia universal.

Indicados nos quadros 5 e 6 encontram-se as graduações com maior freqüência adotadas.

\section{Parâmetros da prática de diagnóstico}

\section{Diagnóstico clínico}

O diagnóstico de câncer é desconhecido em $20 \%$ dos doentes por ocasião do tratamento cirúrgico, sendo

\begin{tabular}{|c|c|}
\hline \multicolumn{2}{|r|}{$\begin{array}{c}\text { Quadro 5 } \\
\text { Escala de desempenho funcional de Karnofsky } y^{54}\end{array}$} \\
\hline Pontos & Descrição \\
\hline 100 & Normal; sem queixas e ausência de doença \\
\hline 90 & Sintomas menores; capaz de efetuar as atividades normais \\
\hline 80 & Poucos sintomas; capaz de efetuar as atividades com esforços \\
\hline 70 & $\begin{array}{l}\text { Cuidados pessoais realizados; incapaz } \\
\text { de efetuar atividades normais }\end{array}$ \\
\hline 60 & $\begin{array}{l}\text { Necessita assistência ocasional; independente } \\
\text { na maioria de suas necessidades }\end{array}$ \\
\hline 50 & Necessita de assistências consideráveis e cuidados freqüentes \\
\hline 40 & $\begin{array}{l}\text { Parcialmente capaz; necessita de cuidados especiais } \\
\text { e assistência }\end{array}$ \\
\hline 30 & Incapaz; hospitalizado e morte não iminente \\
\hline 20 & Doente; necessita de suporte ativo \\
\hline 10 & Moribundo; evolução rápida dos processos fatais \\
\hline 0 & Morte \\
\hline
\end{tabular}

Quadro 6

Escala de deficiência ASIA * (Modificado de Frankel) ${ }^{5,54}$

$\begin{array}{ll}\begin{array}{l}\text { A } \\ \text { Completa }\end{array} & \begin{array}{l}\text { Não há preservação das funções motoras ou da } \\ \text { sensibilidade nos segmentos sacrais S4-S5 }\end{array} \\ \text { B } & \begin{array}{l}\text { Há preservação da função da sensibilidade, } \\ \text { porém não motora caudal em nível neurológico, } \\ \text { estendendo-se até os segmentos sacrais S4-S5 }\end{array} \\ \text { C } & \begin{array}{l}\text { Há função motora preservada caudal em nível } \\ \text { neurológico, e a maioria dos músculos-chave } \\ \text { têmpleta grau de força muscular inferior a 3 }\end{array} \\ \text { D } & \begin{array}{l}\text { Há função motora preservada caudal em nível } \\ \text { neurológico, e pelo menos a metade dos músculos- } \\ \text { chave têm grau de força muscular igual ou superior a } 3\end{array} \\ \text { E } & \text { As funções, sensibilidade e motoras, são normais } \\ \text { Normal } & \end{array}$

*American Spinal Injury Association

o déficit neurológico progressivo geralmente a primeira manifestação da doença ${ }^{10}$. Sintomas de alerta, denominados de red flags, são indicadores para o diagnóstico diferencial das doenças degenerativas da coluna vertebral em relação as metastáticas: dor em período superior a 6 semanas, perda de peso, dor noturna e de repouso, idade superior a 50 anos e ausência de melhora com o tratamento conservador ${ }^{1,7}$ são sugestivas de doença metastática.

As apresentações clínicas das metástases ósseas da coluna vertebral são: dor óssea, fraturas patológicas, dor radicular, mielopatia e deformidade óssea progressiva. Compressão da medula espinhal ocorre entre $8,5 \%$ a $20 \%$ dos doentes com metástases espinhais e o início da sintomatologia está presente após fraturas do corpo vertebral, invasão da neoplasia para o interior do canal vertebral e após remodelação osteoblástica progressiva das vértebras. Sintomas neurológicos ocorrem em 47\% dos doentes, dor em $90 \%$ e a capacidade de deambular 
quando firmado o diagnóstico, em $11 \%$ a $34 \%$. Outros sinais e sintomas presentes na apresentação inicial são: déficit da sensibilidade de $70 \%$ a $80 \%$; paraparesia ou paraplegia em valor superior a $60 \%$; disfunção dos esfíncteres entre $14 \%$ a $77 \%$ dos doentes ${ }^{15}$.

O diagnóstico tardio da doença metastática ocorre com freqüência, apesar da história prolongada dos sintomas de dor e do conhecimento do diagnóstico de câncer primário. Características de "dor suspeita" são: dor radicular de pequena intensidade e persistente (tingling); sensação de "queimação"; dor lancinante; dor na face anterior da coxa, dor "em faixa" na parede torácica, na face posterior da coxa, localizada no dorso; dor de grande intensidade, progressiva e não responsiva a medicação. As neoplasias com maior freqüência associadas às metástases epidurais são: mama, próstata, pulmão ${ }^{32}$. Dor secundária às metástases localizadas no corpo vertebral pode apresentar-se de três formas: 1) dor situada no local da massa do tumor ou devido à destruição do periósteo - tem como característica não aumentar com os movimentos e ser constante; 2) dor radicular secundária à extensão da massa do tumor com compressão do nervo espinhal; 3 ) dor axial de natureza mecânica, que aumenta com movimentos e diminui com repouso, secundária geralmente a anormalidades estruturais da coluna vertebral e indicativo de instabilidade ${ }^{43}$.

Estadiamento preliminar e cirurgia de urgência: 0 diagnóstico do doente com metástase(s) na coluna vertebral, como a primeira manifestação da doença, ocorre em duas situações clínicas distintas em relação ao período de evolução: o doente encontra-se estável, com o estado geral clínico satisfatório e com mínimos déficits neurológicos; instabilidade clínica, estado geral debilitado e com déficit neurológico progressivo ou com a instalação de paraplegia em período inferior a 24 horas.

Estabilidade clínica e neurológica: o período investido na investigação da origem da neoplasia primária e possíveis metástases para outros órgãos justificam os dias ou semanas para o estadiamento preciso da doença, permitindo a escolha da melhor modalidade de tratamento. Deve ser multidisciplinar, com a participação do oncologista, cirurgião espinhal, radiologista, psicólogo, assistente social e outras especialistas pertinentes ao caso.

Instabilidade clínica e déficit neurológico progressivo ou definitivo: descrito no tópico prévio, em $20 \%$ dos casos o diagnóstico de câncer é desconhecido por ocasião da indicação de cirurgia, e déficit motor progressivo é a primeira manifestação da doença ${ }^{10}$. Paraparesia e paraplegia estão presentes em valor superior a $60 \%$ dos casos ${ }^{15}$. Paraplegia em período superior a 24 horas raramente é revertida ${ }^{15}$. O primeiro atendimento desse doente, com freqüência, é no serviço de pronto atendimento com a participação das equipes de clínica médica, cirurgia geral, neurocirurgia e ortopedia, raramente contando com a participação de equipe multidisciplinar para o completo estadiamento da doença metastática. Tratamento cirúrgico é indicado em regime de urgência a fim de preservar ou reverter as funções neurológicas deficitárias.

$\mathrm{O}$ estadiamento realizado em período inferior a 12 horas permite efetuar o mínimo de exames complementares, porém necessários. São estes: exames laboratoriais de rotina (hemograma, glicemia, VHS, eletrólitos, coagulograma, funções hepática e renal); análise química, microscópica e microbiológica de urina (infecção do trato urinário devido à retenção urinária ou da sondagem vesical prévia); eletrocardiograma (a faixa etária mais freqüente é entre as quinta e sétima décadas); radiografias do tórax e abdômen (pesquisa dos tumores primários mais freqüentes); radiografias da coluna vertebral nas projeções ântero-posterior e perfil (destruição óssea, fraturas patológicas, planejamento cirúrgico para a estabilização segmentar vertebral); ultra-sonografia do abdômen e pelve (quando há suspeita da neoplasia primária originar-se no espaço intracavitário); tomografia axial computadorizada da coluna vertebral com atenuação radiológica para a avaliação de osso, tecido neural e paravertebral no local anatômico da neoplasia, abrangendo três ou quatro níveis segmentares no sentido cranial e caudal à neoplasia (útil no planejamento da estabilização segmentar cirúrgica). Ressonância magnética da coluna vertebral sem contraste paramagnético, com imagens sagitais nos segmentos cervical, torácico e lombar e, com cortes axiais apenas no(s) nível(s) da(s) neoplasia(s). Este exame é considerado o padrão de diagnóstico de imagem na doença metastática da coluna vertebral, porém não disponível na maioria dos hospitais e tampouco em regime de urgência ${ }^{59}$.

As recomendações para o estadiamento preliminar no doente com instabilidade clínica e déficit neurológico progressivo em período inferior a 24 horas, em que o tratamento cirúrgico é provável de ser efetuado em regime de urgência, são apresentadas no quadro 7.

\footnotetext{
Quadro 7

Exames complementares para o tratamento cirúrgico de urgência

Dosagens químicas do sangue, hemograma, análise

química de urina, eletrocardiograma

Radiografias de tórax, abdômen, coluna

vertebral (cervical, torácica, lombar)

Ultra-sonografia de abdômen e pelve

*Ressonância magnética da coluna vertebral (exame de eleição)

**Tomografia axial computadorizada do(s) nível(s) comprometido(s).

*ressonância magnética com imagens sagitais sem contraste nos

segmentos cervical torácico e lombar, associadas a imagens sagitais

e axiais com contraste no(s) nível(s) comprometido(s)

**tomografia axial computadorizada no(s) nível(s) comprometido(s),

com atenuação para osso, três ou quatro níveis nos sentidos

cranial e caudal (para a fixação em osso sem neoplasia)
} 


\section{Diagnóstico de imagem}

Radiografia simples: não apresenta valor presuntivo no diagnóstico de lesões metastáticas situadas na coluna vertebral e são falso-negativos em $10 \%$ a $17 \%$ dos casos. Porém, são úteis para acessar alterações qualitativas das vértebras, o local anatômico vertebral do envolvimento da neoplasia e a integridade estrutural da coluna vertebral. A maioria das metástases são osteolíticas, mas as neoplasias de origem na próstata e na mama são osteoblásticas. Erosões das margens corticais do canal vertebral é sinal precoce da ação osteolítica da neoplasia e a possibilidade de se tratar de metástase vertebral é de $85 \%$ se houver colapso superior a $50 \%$ da vértebra e, de $31 \%$, se houver destruição isolada do pedículo ${ }^{39}$. O diagnóstico diferencial entre as metástases e os processos infecciosos consiste na preservação das margens ósseas do espaço discal intervertebral na metástase e a destruição das margens referidas nas infecções ${ }^{15}$.

Tomografia axial computadorizada: é sensível para as imagens de destruição óssea das vértebras e identifica a extensão e distribuição das alterações líticas ou blásticas das metástases. É útil para visibilizar possíveis fragmentos ósseos do muro posterior das vértebras no interior do canal vertebral e na avaliação do alinhamento da coluna vertebral nas reconstruções sagitais, especialmente nas regiões anatômicas onde as radiografias são deficientes para a avaliação da coluna vertebral: região occipital a C3 e no nível dos ombros $\left(\mathrm{C} 6\right.$ a T4) ${ }^{43}$. A avaliação das vértebras nos sentidos cranial e caudal deve incluir até quatro vértebras quando o objetivo é a fixação com parafusos pediculares, os quais não devem ser aplicados e locados em vértebras comprometidas com a destruição óssea das metástases. A mielografia pode ser associada à tomografia computadorizada (mielotomografia) quando não for possível o uso da ressonância magnética ${ }^{39,59}$. Aplicado para o planejamento das técnicas e táticas cirúrgicas e deve ser associada como complemento à ressonância magnética da coluna vertebral.

Ressonância magnética: é a modalidade de imagem de escolha para a investigação e o diagnóstico das metástases da coluna vertebral, fornecendo informações da extensão e distribuição da neoplasia em relação ao tecido nervoso. A especificidade é de 97\%, a sensibilidade é de $93 \%$ e a acurácia é de $95 \%$ no diagnóstico das mielocompressões ${ }^{2}$. Os objetivos são o estadiamento da doença metastática na coluna vertebral e o planejamento do tratamento escolhido. A investigação inclui toda a extensão da coluna vertebral com imagens sagitais e sem contraste, reservando as imagens com o agente de contraste para as regiões com metástase vertebral, paravertebral e epidural nos planos axial e sagital ${ }^{1}$. O uso do gadolinium aumenta a impregnação do agente nos corpos vertebrais normais e a presença de metástases incipientes pode não ser detectada. A ressonância apresenta alta sensibilidade no diagnóstico de alterações incipientes de neoplasia na medula óssea dos corpos vertebrais, sendo evidência precoce de doença sistêmica nos doentes com câncer ${ }^{43}$.

Cintilografia do esqueleto: é útil para detectar implantes de metástases no esqueleto, porém a especificidade é baixa devido a resultados falso-positivos na presença da doença degenerativa da coluna vertebral, fraturas e doença metabólica com acometimento do osso $^{43}$.

Angiografia e embolização: angiografia complementada com embolização vascular da neoplasia está indicada em tumores hipervascularizados quando houver suspeita prévia da possibilidade de ocorrer sangramento de grande volume durante a exérese da neoplasia bem como para a localização da artéria de Adamkiewicz nas neoplasias localizadas entre os níveis T8 e L1 com extensão paravertebral. Neoplasias metastáticas de melanoma, hipernefroma, carcinoma da tiróide apresentam indicação de embolização, no período de 18 a 24 horas anteriores à cirurgia; após esse período, ocorre a revascularização do tumor ${ }^{43,53}$. Complicações neurológicas ocorrem em aproximadamente $2 \%$ dos doentes seguidas à angiografia e complicações locais ou sistêmicas, em $4 \%$ a $10 \%{ }^{42}$.

Biopsia: é indicada para se obter o diagnóstico histológico da metástase, antecedendo a cirurgia definitiva, ou para a escolha do tratamento apropriado, realizado com maior freqüência na suspeita da doença metastática. Em doentes submetidos à radioterapia, a biopsia pode estar indicada para documentar a recorrência da neoplasia. Sumariadas no quadro 8 recomendações para o procedimento descrito.

\footnotetext{
Quadro 8

Indicações para a biopsia vertebral

Diagnóstico histológico da neoplasia

Escolha da modalidade de tratamento (cirurgia ou radioterapia)

Planejamento da técnica e tática cirúrgica

Procedimento de rotina no doente com estabilidade clínica e neurológica
}

A escolha de uma das três modalidades de técnicas de biopsias depende do objetivo do tratamento e do estadiamento da doença neoplásica, a seguir, sumariados:

- Biopsia para exérese radical da metástase: indicada nos tumores situados nos elementos ósseos posteriores das vértebras, tais como osteoblastoma e cisto ósseo aneurismático, fornece o diagnóstico histológico e o tratamento definitivo. 
- Biopsia a céu aberto: a incisão cirúrgica não deve interferir em uma futura incisão para o procedimento cirúrgico definitivo. A hemostasia deve ser meticulosa a fim de evitar a presença de hematomas residuais no leito da área cirúrgica, devido à possibilidade de células neoplásicas se disseminarem através das fáscias dos músculos ${ }^{53,59}$

- Biopsia percutânea por agulha: efetuada sob radioscopia ou tomografia axial computadorizada. Complicações possíveis são sangramentos, pneumotórax e dor. A ausência do diagnóstico histológico ocorre em aproximadamente 25\% dos casos, atribuída a falhas da técnica do procedimento, tumores com necrose, lesões vasculares e tumores blásticos densos.

\section{Parâmetros da prática de tratamento}

Duas publicações são citadas como referências para o assunto ${ }^{28,44}$. Os conceitos de estabilidade e estadiamento anatômico da coluna vertebral são apresentados nas opções das vias de acesso cirúrgico.

A escolha do tratamento é individual e relacionada ao período de sobrevivência, à capacidade de deambular e à estabilidade da coluna vertebral.

\section{Recomendações no tratamento das metástases da coluna vertebral ${ }^{44}$}

Padrão: não há evidência suficiente para a recomendação de um tratamento padrão.

Diretrizes: métodos cirúrgicos para a descompressão e estabilização são recomendados na situação de instabilidade da coluna vertebral em doentes com déficit neurológico progressivo sem paraplegia, disfunção dos esfíncteres ou dor significativa. O objetivo da intervenção cirúrgica consiste na melhora da dor e/ou da qualidade de vida, necessariamente não relacionado ao período de sobrevivência. A descompressão cirúrgica e a fusão devem ser consideradas com cuidados para doentes com paraplegia, exceto quando o propósito do método cirúrgico é indicado para obter o diagnóstico.

O objetivo do tratamento com a cirurgia é a descompressão da medula espinhal, e as recomendações nas indicações são descritas no quadro 9.

Opções: a radioterapia deve ser considerada como opção de tratamento nos doentes com paraplegia relacionada à doença metastática da coluna vertebral. A radioterapia também pode ser considerada como opção de tratamento em doentes com a capacidade preservada

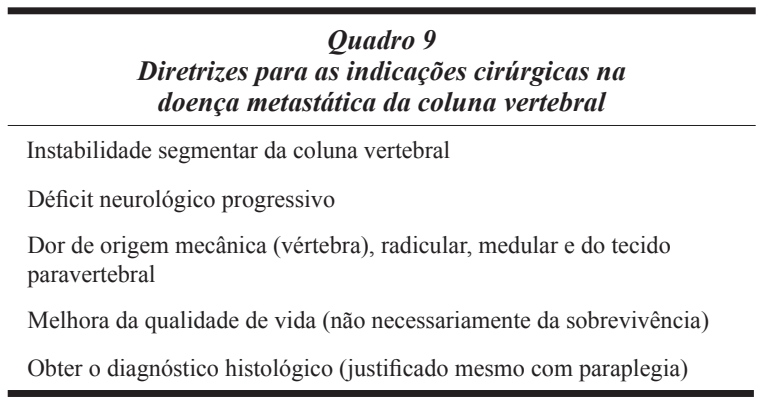

de deambular, com mínimo déficit neurológico e dor, em especial naqueles doentes com o conhecimento prévio de serem portadores de tumores radiossensíveis. Doentes com déficit neurológico progressivo, em vigência de tratamento com a radioterapia, devem ser considerados para o tratamento cirúrgico em regime de urgência para a descompressão e/ou estabilização.

Conclusões: a intervenção cirúrgica é benéfica na presença da doença metastática situada na coluna vertebral, em que concerne o alívio dos sintomas de dor causado pela metástase e a melhora da qualidade de vida. Todavia, não há evidência suficiente que o período de sobrevivência seja mais prolongado após a cirurgia. A descompressão e a fusão obtidas através das várias abordagens e modalidades de cirurgias propostas, mantêm a estabilidade da coluna vertebral durante o período de sobrevivência. Doentes com déficits neurológicos significativos, porém não paraplégicos, podem apresentar melhora considerável das deficiências com o tratamento cirúrgico, visando métodos de descompressão e estabilização. Há evidência insuficiente para recomendar a intervenção cirúrgica de rotina nos doentes com paraplegia. Radioterapia sem a intervenção cirúrgica deve ser reservada nas seguintes categorias de doentes: o conhecimento prévio de portadores de tumores radiossensíveis; aqueles com mínimos sintomas de dor e ausência de déficit neurológico; tratamento paliativo nos doentes com paraplegia.

\section{Tratamento da doença metastática epidural espinhal: revisão da literatura}

Os objetivos são de sumariar os dados dos resultados das várias modalidades de tratamentos e as recomendações de uso dos tratamentos.

A qualidade da literatura avaliada, as recomendações para o uso das modalidades dos tratamentos e os indicadores prognósticos com a finalidade de avaliar os resultados, são baseados em evidências com respeito à qualidade da literatura e valor das recomendações dos tratamentos ${ }^{28}$.

Medicamentos com esteróides: evidência Classe I (obtido de estudos apropriados, randomizados e con- 
trolados). Nível A de recomendação (boa evidência Classe I - que o procedimento deve ser especificamente considerado como intervenção para a condição).

Há boa evidência no suporte para o uso de drogas contendo esteróides em doentes com o diagnóstico recente de doença metastática associado à disfunção da medula espinhal. Doentes sem história prévia de câncer, apresentando, como primeira manifestação da doença, uma massa paraespinhal não diagnosticada anteriormente, deve ser evitado o início do medicamento esteróide até o diagnóstico de certeza, especialmente nos jovens. As propriedades oncolíticas dos esteróides podem retardar o diagnóstico, particularmente nos linfomas e timomas. $\mathrm{O}$ esteróide mais empregado é a dexametasona. A metilprednisolona, de uso mais freqüente no trauma agudo da medula espinhal, também é aplicado para essa finalidade. As drogas contendo esteróides reduzem o edema vasogênico, são protetoras das ações da peroxidase lipídica e hidrólise lipídica, previnem a isquemia e o acúmulo de cálcio intracelular e auxiliam no suporte do metabolismo energético da célula.

A dose ótima do dexametasona não é definida, porém, a dose inicial de $10 \mathrm{mg}$ seguida de $16 \mathrm{mg} / \mathrm{dia}$, com a diminuição gradual no período de semanas até a retirada é apropriada.

Quimioterapia e terapia hormonal: o raciocínio do uso da quimioterapia consiste na localização anatômica do espaço epidural situar-se na face sistêmica da barreira hemato-encefálica e em contato com a neoplasia metastática. A maioria das metástases não apresenta sensibilidade à ação dos agentes quimioterápicos, reservados para os linfomas de Hodgkin e não-Hodgkin, câncer de mama e tumores de células germinativas. A terapia hormonal é benéfica em doentes com câncer da próstata e de mama, quando sensíveis a essa modalidade de tratamento complementar ${ }^{2,39}$.

Laminectomia descompressiva posterior: evidência Classe II (obtido de estudos apropriados, com controle, sem randomização); Nível D de recomendação (evidência razoável - Classe II - que o procedimento deve ser excluído de consideração como intervenção para a condição).

Foi método popular para o tratamento das metástases da coluna vertebral até o início dos anos de $1980^{6}$, devido à facilidade técnica não necessitar de reconstrução espinhal ou fixação e oferecer riscos mínimos para o doente no ato operatório. $\mathrm{O}$ índice das complicações pós-operatórias é de $11 \%$ e inclui instabilidade da coluna vertebral, infecções e deiscência da sutura.

Os resultados da laminectomia, como única modalidade de tratamento, são comparados à radioterapia como única modalidade de tratamento e, ainda, à associação de laminectomia seguida de radioterapia, este último com resultados mais favoráveis.
Os resultados apresentam evidências de que a laminectomia, como única modalidade de tratamento, oferece mínimo benefício neurológico e morbidade significante, o que resultou na determinação de que a radioterapia, no período descrito, assumisse a primeira escolha como modalidade de tratamento.

O uso indiscriminado da laminectomia descompressiva apresentava como seu destino o fracasso, devido ao fato de a metástase situar-se anteriormente no corpo vertebral, ventral em relação às estruturas neurológicas. Não é possível uma descompressão satisfatória sem a retração significativa do saco tecal, com comprometimento maior das funções neurológicas. A laminectomia pode ocasionar ou aumentar instabilidade pré-existente da coluna vertebral, que por sua vez evolui para deformidade maior, resultando em dor, mais deformidade e comprometimento das funções neurológicas. Baseados nos dados prévios, a laminectomia, sem o auxílio de instrumentação de fixação interna, não deve ser indicado para o tratamento da doença metastática da coluna vertebral, exceto quando a neoplasia situar-se posteriormente, nas lâminas e processo espinhoso. Apesar do exposto, essa modalidade de tratamento continua sendo indicada e realizada.

Os resultados da laminectomia são favoráveis quando suplementado com a instrumentação complementar (parafusos pediculares) e a fusão $0^{28}$.

Descompressão circuferencial da medula espinhal: evidência Classe I (obtido de estudos apropriados, randomizados e controlados); Nível A de recomendação (boa evidência - Classe I - que o procedimento deve ser especificamente considerado como intervenção para a condição).

A fim de se obter a descompressão circunferencial, as abordagens cirúrgicas devem ser planejadas de acordo com o local anatômico do tumor situada na coluna vertebral, com o objetivo da descompressão completa da neoplasia da medula espinhal. As abordagens são classificadas em via anterior (por exemplo, transtorácica ou retroperitoneal) e posterior, incluindo as vias póstero-laterais (por exemplo, laminectomia, transpedicular, costotransversectomia ou extracavitária lateral). Associadas à descompressão da medula espinhal, a reconstrução e a imediata estabilização da coluna vertebral constituem os pilares do tratamento cirúrgico atualmente.

As indicações cirúrgicas incluem: tumores radioresistentes (sarcomas e neoplasias do pulmão, cólon e do rim); instabilidade da coluna espinhal; achados cínicos significativos de compressões neurais, secundários à retropulsão óssea e deformidade; dor intratável e refratária ao tratamento medicamentoso; falha da radioterapia (déficit neurológico progressivo e limite da tolerância da medula espinhal à radioterapia). 
A cirurgia deve ser escolhida como a primeira modalidade de tratamento em todos os doentes com o recém diagnóstico de doença metastática da coluna vertebral e quando não há indicações para a radioterapia como primeira escolha de tratamento.

Citado em publicações ${ }^{2,28,29,30,40}$, Patchell e col. ${ }^{41}$ apresentam resultados de estudo randomizado e com controle, a fim de avaliar os resultados do tratamento com a cirurgia descompressiva para metástases da coluna vertebral seguida de radioterapia, comparada a radioterapia convencional, como modalidade única de tratamento. Os dois grupos são tratados com o mesmo protocolo de esteróides e ambos são submetidos à mesma dose de irradiação (30 Gy). Os grupos são representados por 50 doentes cirúrgicos e 51 submetidos à radioterapia. Doentes submetidos ao tratamento cirúrgico mantiveram, por período significativamente maior, a capacidade de deambular e as funções dos esfíncteres quando comparados aos doentes submetidos à radioterapia como modalidade única de tratamento. Ainda, 56\% dos doentes com ausência da capacidade de deambular readquiriram essa capacidade, quando comparados a $19 \%$ dos doentes do grupo submetidos à radioterapia. A sobrevivência não apresentou diferença significativa entre os dois grupos.

Radioterapia convencional: evidência Classe I (obtido de estudos apropriados, randomizados e controlados); nível A de recomendação (boa evidência - Classe I - que o procedimento deve ser especificamente considerado como intervenção para a condição) ${ }^{28}$.

As indicações para a radioterapia incluem: tumores radiossensíveis (linfoma, mieloma múltiplo, carcinoma pulmonar de pequenas células, seminoma dos testículos, neuroblastoma e tumor de Ewing); previsão de sobrevivência inferior a 3 ou 4 meses; incapacidade de tolerar o tratamento cirúrgico; déficit neurológico completo inferior ao nível da mielocompressão por mais de 24 a 48 horas; envolvimento neoplásico difuso ou em vários níveis da coluna vertebral (quadro 10). O portal de irradiação padrão envolve o nível com a metástase vertebral e margem de $5 \mathrm{~cm}$, incluindo duas vértebras no sentido cranial e caudal. A dosagem total de irradiação é geralmente de 3000 cGy (2000 a 4000 cGy) e é administrado no período de 10 a 14 dias, com doses maiores no início do tratamento e diminuição gradual até o término. Doentes com tumores radiossensíveis apresentam resultado funcional melhor quando comparados com aqueles com tumores radiorresistentes. Doentes com tumores isolados e situados na coluna vertebral, geralmente no corpo vertebral e com ausência de invasão epidural, uma dose única (geralmente $8 \mathrm{~Gy}$ ), oferece alívio dos sintomas da dor com eficácia igual aos regimes de irradiação em doses fracionadas.

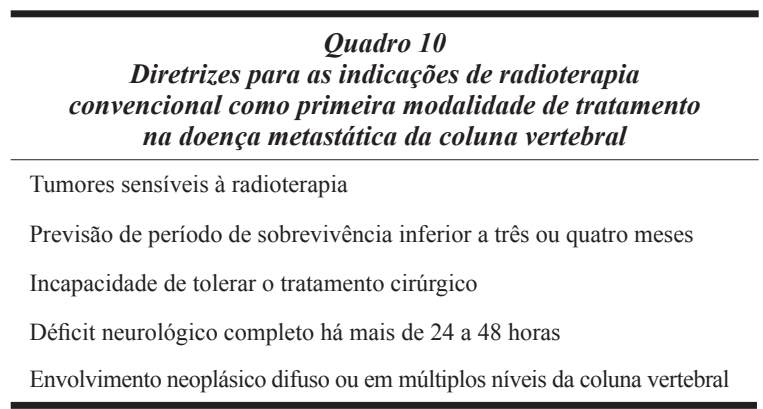

Nos doentes com as indicações descritas previamente para o tratamento primário ser a cirurgia, a radioterapia complementa o tratamento. Em doentes com tumores radiorresistentes, com expectativa de sobrevivência reduzida e que não tolerariam o procedimento cirúrgico, a radioterapia deve ser a primeira modalidade de tratamento escolhida.

Radioterapia não-convencional: evidência Classe III (séries de casos, estudos comparativos, relatos de casos, opinião de especialista, ensaio randomizado e controlado com falhas significativas); nível C de recomendação (evidência pobre - Classe III - para o apoio da recomendação do procedimento ser especificamente considerado ou que confere vantagem sobre as intervenções concorrentes).

A irradiação convencional incide no sítio do tumor e nos tecidos adjacentes normais, com a possibilidade do desenvolvimento de mielopatia secundária à irradiação. A radioterapia não convencional inclui a radiocirurgia em dose única e a radioterapia esterotáxica de dose fracionada, técnicas capazes de irradiar o alvo e poupar os tecidos normais adjacentes, diminuindo, teoricamente, possíveis lesões secundárias da irradiação à medula espinhal.

A radioterapia não-convencional é segura, mas a eficácia não é provada em relação às modalidades convencionais de radioterapia e cirurgia. Essas provas são necessárias antes que recomendações da modalidade descrita sejam determinadas.

Conclusões: o tratamento da doença metastática da coluna vertebral modificou durante os últimos vinte anos, não sendo a laminectomia a única modalidade de cirurgia oferecida para o doente, com o mínimo de benefícios e riscos inerentes aos tratamentos cirúrgicos, salvo em tumores situados posteriormente nas vértebras. Os objetivos dos procedimentos cirúrgicos que visam à descompressão da medula espinhal da neoplasia, reconstrução e estabilização da coluna vertebral, apresentam eficácia superior à radioterapia convencional como modalidade única de tratamento, nos aspectos da preservação e resgate das funções neurais, especialmente na capacidade da deambulação e das funções dos esfíncteres. O alívio dos sintomas da dor também são consideráveis na descompressão circunferencial 
da medula espinhal. A radioterapia convencional tem papel de terapia adjuvante, assim como terapia primária nos doentes incapazes de tolerar ou se beneficiar do procedimento cirúrgico. O papel da radioterapia não convencional resta ser elucidado ${ }^{28}$.

\section{Métodos e vias de acesso cirúrgico}

As abordagens para o tratamento da doença metastática da coluna vertebral são categorizadas em anterior, posterior e, as abordagens de acesso, combinadas. A melhor escolha da via de acesso relaciona o canal vertebral e a medula espinhal ao nível anatômico da lesão, da posição e extensão da massa tumoral e da compressão óssea. A integridade da coluna vertebral é o objetivo, e devem ser consideradas as reconstruções e as estabilizações ${ }^{18,19}$.

O planejamento da cirurgia deve incluir a preocupação de restabelecer as características anatômicas e biomecânicas prévias à destruição óssea da coluna vertebral, dentro das limitações impostas pela evolução natural da doença metastática (quadro 11).

Quadro 11
Objetivos no tratamento cirúrgico da doença
metastática da coluna vertebral

Critérios de instabilidade: a definição da instabilidade clínica é a perda da capacidade da coluna vertebral, sob cargas fisiológicas, de manter as relações anatômicas normais entre as vértebras, com lesões secundárias aos nervos espinhais e medula espinhal, com a conseqüente deformidade ou dor devido às alterações estruturais ${ }^{19}$.

Os vários critérios propostos para a graduação da instabilidade da coluna vertebral não apresentam validade clínica e radiológica definida na presença da doença metastática ${ }^{20}$. Critérios para as definições da instabilidade presentes na doença degenerativa e no trauma diferem daqueles da doença metastática, lento e progressivo no primeiro e de início súbito e não progressivo no segundo. A instabilidade vertebral secundária e as destruições ósseas e ligamentares da neoplasia são progressivas e dinâmicas, sendo necessárias as análises de instabilidade no momento do diagnóstico e que irão ocorrer seguindo a evolução natural da doença ${ }^{18}$.

Critérios de instabilidade vertebral na presença de metástases são $0^{47,48}$ : destruição de duas ou mais áreas anatômicas da vértebra (definido por Denis ${ }^{14}$ ) (figura 4A); destruição de área igual ou maior de 50\% da massa óssea do corpo vertebral (figura 4B); ângulo de cifose superior a 20 ou 30 graus (figura 4C); envolvimento de destruição neoplásica das mesmas áreas vertebrais em dois ou mais segmentos, no sentido cranial e/ou caudal (figura 4D). A densidade mineral das vértebras e as características biomecânicas regionais da coluna são fatores estáticos que influenciam de maneira dinâmica a estabilidade da coluna vertebral ${ }^{20}$.

A

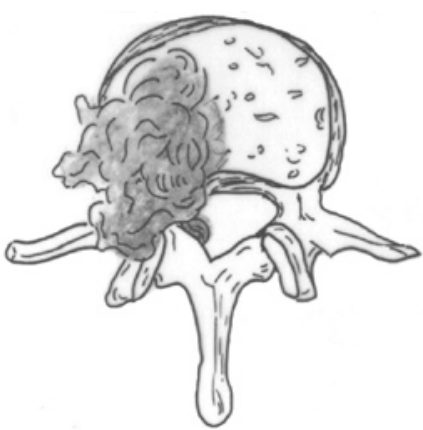

B

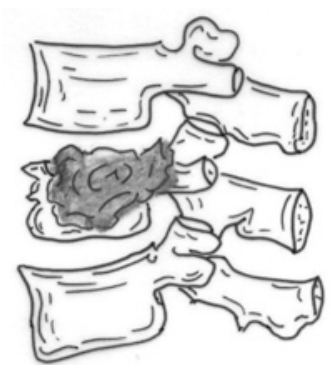

C

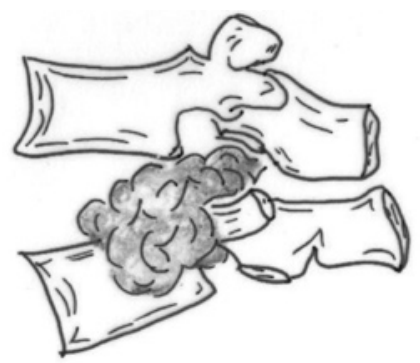

D

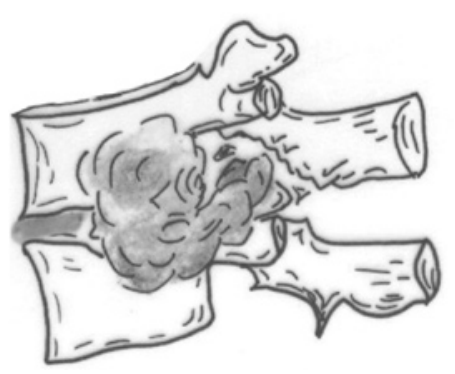

Figuras 4 A,B,C,D - Critérios de instabilidade segmentar na presença de metástases vertebrais ${ }^{47,48}$.

Kostuik e col. ${ }^{31}$, em 1988, definiram estabilidade da coluna vertebral utilizando o modelo de três colunas de Denis ${ }^{14}$ e dividindo a vértebra em metade direita 
e esquerda, e o corpo vertebral no sentido anterior e posterior, totalizando seis segmentos. É considerado estável se apenas até dois dos segmentos estiverem acometidos por neoplasia e instável se três ou mais segmentos estiverem envolvidos (figura 5).

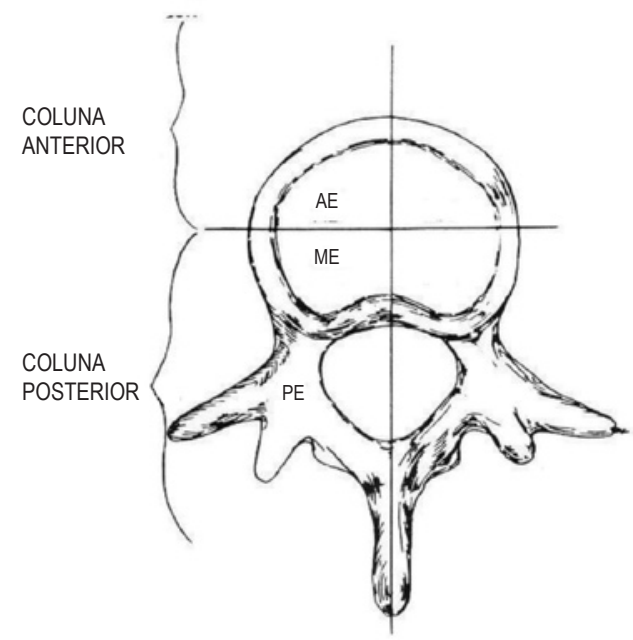

Figura 5 (modificado de Kostuik ${ }^{31}$ ) - Modelo de três colunas de Denis ${ }^{14}$ subdividido em seis colunas de Kostuik ${ }^{31}$. Critério de estabilidade na doença metastática da coluna vertebral.

Critérios anatômicos de estadiamento: Weinstein-Boriani-Biagini ${ }^{8}$, em 1996, elaboraram a classificação anatômica do local dos tumores primários, aplicado também para o planejamento cirúrgico e o estadiamento das metástases da coluna vertebral. Os objetivos do sistema são de padronizar a nomenclatura e de relacionar o local anatômico do tumor com as estruturas paravertebrais e o tecido nervoso a fim de realizar a exérese cirúrgica da neoplasia com margens histológicas seguras. O sistema não considera o tipo histológico do tumor ou prognóstico do doente. $\mathrm{O}$ foco da análise histológica do tumor consiste na presença da neoplasia no espaço epidural com invasão da dura-máter e pedículo da vértebra, não sendo possível obter a exérese completa da neoplasia nessa situação ${ }^{8}$ (figura 6).

Acesso cirúrgico à junção crânio-cervical ${ }^{15}$ : os limites anatômicos são o forâmen magnum e as vértebras de $\mathrm{C} 1$ e $\mathrm{C} 2$. As estruturas contidas nesses limites ósseos incluem as artérias vertebrais, a medula espinhal, os nervos cranianos inferiores e o espaço subaracnóideo com o líquido cefalorraquiano. A descompressão deve ser obtida da mesma linha de vetor da compressão tumoral.

- Via transoral-transpalatofaríngea: confere exposição ventromedial da coluna vertebral, nos limites anatômicos ósseos da região média do clivus ao espaço intervertebral de $\mathrm{C} 2$ a $\mathrm{C} 3$. A língua ou palato pode ser dividido para se obter maior exposição.

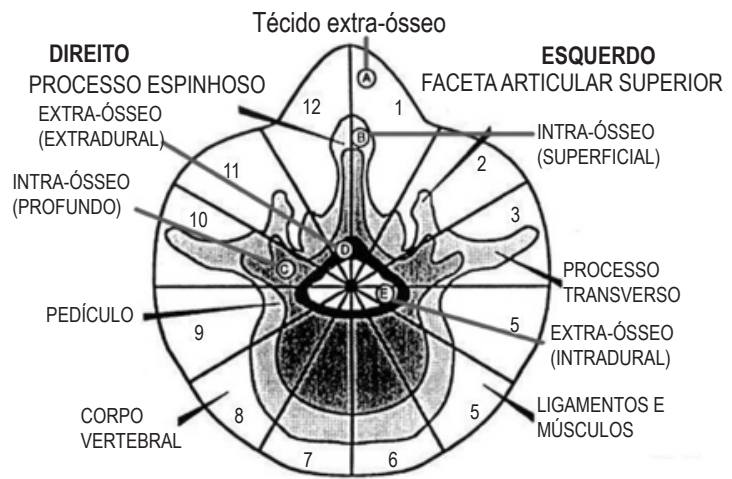

Figura 6 (modificado de Boriani e col. ${ }^{8}$ ) - Classificação anatômica do local do tumor de Weinstein-Boriani-Biaginis. Aplicado para o planejamento cirúrgico e estadiamento das metástases da coluna vertebral.

- Via extrafaríngea-lateral: outra opção para as regiões do clivus e as vértebras de $\mathrm{C} 1$ e $\mathrm{C} 2$. É limitada devido os ramos da mandíbula, glândulas parótidas, osso hióide, nervo hipoglosso e as artérias carótidas (figura 7).

- Via posterior: acesso à região posterior do forâmen magnum e à região lateral para o bulbo jugular. Associa a incisão padrão dorsal e medial com a abordagem cerebelar lateral e inclui a opção da retirada do processo mastóide e côndilo occipital ${ }^{15}$.

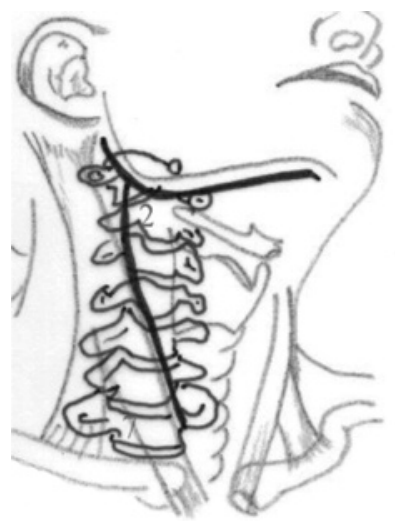

Figura 7 - Via extrafaríngea-lateral: incisão cirúrgica submandibular com extensão cervical ântero-lateral.

As três abordagens, quando associadas, permitem a exposição circunferencial da coluna cervical proximal e podem ser combinadas ainda com exposições cirúrgicas para regiões da base do crânio ${ }^{38}$.

- Via retrofaríngea: abordagem cervical anterior e lateral alta, para o acesso do forâmen magnum. É uma alternativa aos acessos trans-oral e póstero-lateral ${ }^{58}$. 
Opções para se obter a estabilização são: fixação occipito-cervical associada a parafusos nas massas ósseas vertebrais ou nos pedículos ${ }^{19}$.

Acesso cirúrgico à coluna cervical subaxial:

- Via retrofaríngea lateral: é a via anterior padrão habitualmente usado nas doenças degenerativas e traumáticas da coluna cervical. A exposição inclui as vértebras de $\mathrm{C} 2$ a $\mathrm{T} 1$ e permite a corpectomia vertebral do(s) nível(s) com neoplasia, reconstrução e estabilização das regiões anteriores da coluna cervical ${ }^{11,15}$.

- Via posterior: cifose é comum quando vários níveis vertebrais estão envolvidos com metástases e a fixação com parafusos nas massas laterais das vértebras ou hastes para segmentos de maiores extensões de acometimento neoplásico podem ser associados à estabilização anterior efetuada previamente ${ }^{19}$.

\section{Acesso cirúrgico à coluna torácica:}

- Via transesternal: indicada para as metástases localizadas nas vértebras de T1 a T3. A via transesternal permite o acesso anterior e, na linha média, freqüentemente complementada com a abordagem cervical ântero-lateral ${ }^{18,20,46}$.

- Via transesternal ou toracotomia póstero-lateral: indicada nas metástases de T3 a T4. O acesso apresenta limitações à exposição da coluna vertebral devido à presença dos grandes vasos, situados anteriormente. A via alternativa é a combinação das abordagens cervical ânterolateral, esternotomia medial parcial e toracotomia ântero-lateral ou denominado de trap door. As vantagens dessa abordagem é a de não ser necessária a secção da clavícula e de preservar a junção esterno-clavicular; as desvantagens, o período cirúrgico prolongado, a morbidade pós-operatória e de ser inconsistente com os objetivos do tratamento da doença metastática, que é paliativo na maioria dos casos. Conseqüentemente, a via póstero-lateral é a mais recomendada para a região de $\mathrm{T} 3$ a $\mathrm{T} 4^{18,20}$.

- Toracotomia: indicada para os de níveis de T5 a T10. O hemitórax direito é preferido para evitar a presença do coração e do arco da aorta no campo operatório, porém, a depender da extensão do tumor paravertebral, os lados direito ou esquerdo são abordados. Para as lesões envolvendo os níveis de T5 a T6, o quinto arco costal é retirado. Nos níveis de T7 a T8, a costela localizada no nível cranial ao epicentro do tumor (sexto ou sétimo, respectivamente), é removida. Em T9 a T10, a costela dos dois níveis no sentido cranial (sétimo ou oitavo, respectivamente), é removida ${ }^{18,20}$.
- Via posterior: a laminectomia está indicada para os tumores situados posteriormente em relação ao saco tecal e/ou com envolvimento das lâminas e processo espinhoso.

-Via póstero-lateral: permite a descompressão dos elementos espinhais anteriores e posteriores em tempo cirúrgico único. A costotransversectomia é adequada para a visualização parcial dos níveis de T6, aproximadamente, a T12. A exposição da região torácica alta é limitada devido às relações anatômicas da coluna vertebral com escápula, músculos rombóide e trapézio. A abordagem extracavitária lateral requer a ressecção maior da costela e dessecação mais ampla para a visibilização adequada da coluna vertebral. $\mathrm{Na}$ situação em que a neoplasia acomete três ou mais vértebras contíguas, a depender da expectativa de vida do doente, a via pósterolateral é mais adequada, suplementada com a reconstrução parcial do corpo vertebral e a estabilização segmentar ${ }^{3,11,18,20}$ (figura 8).

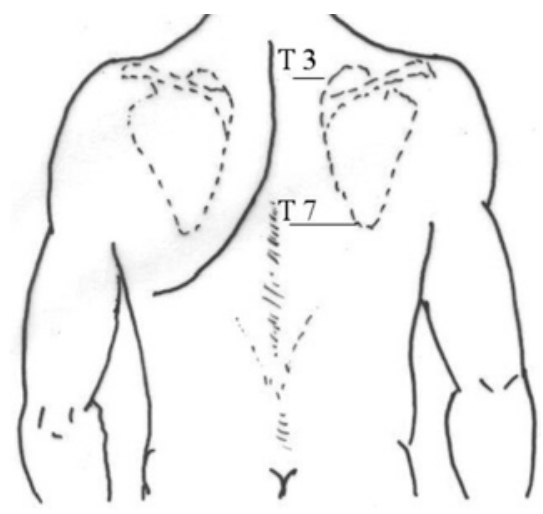

Figura 8 - Via póstero-lateral torácica. A incisão cirúrgica no nível anatômico da vértebra de T3 é complementada com a extensão lateral no dorso.

\section{Acesso cirúrgico à junção toracolombar:}

- Via retroperitoneal combinada com toracotomia: indicada para os tumores situados de T11 a L1. As abordagens abertas simultâneas do tórax e da cavidade abdominal aumentam a morbidade pós-operatória. O lado esquerdo do doente é preferido devido a maior facilidade de afastar o baço do que o fígado e, na eventual lesão da artéria aorta, a sua reparação é mais viável do que a da veia cava inferior. A região póstero-lateral do diafragma pode ser seccionada e liberada a fim de expor as vértebras de L1 e L2. O decúbito é a posição lateral e a incisão, situa-se sobre as costelas inferiores do mesmo lado. 
- Via póstero-lateral: indicada para os doentes com expectativa de sobrevivência limitada. Deve ser suplementada com instrumentação $0^{3,11,15,18,20}$.

Acesso cirúrgico à coluna lombar:

- Via ântero-lateral retroperitoneal: indicada para a abordagem das vértebras de L2 a L4. O decúbito é o lateral e, de preferência, à esquerda. As incisões variam do nível da décima segunda costela a níveis abdominais inferiores ${ }^{15,18,20}$.

- Via póstero-lateral: preferida para os níveis de L5 ao sacro devido à presença dos grandes vasos nesta região e à dificuldade técnica da dessecação da neoplasia, fixação e estabilização da coluna vertebral ${ }^{3,11,15,18,20}$.

- Via posterior: previamente descrita ${ }^{15,18,20}$.

O quadro 12 relaciona os níveis anatômicos das vértebras com as opções dos acessos cirúrgicos para o tratamento da doença metastática da coluna vertebral.

Quadro 12

Níveis vertebrais e opções dos acessos cirúrgicos

\begin{tabular}{|c|c|c|}
\hline Junção crânio-cervical: & occipital a $\mathrm{C} 2$ & $\begin{array}{l}\text { Via transoral-transpalatofaríngea } \\
\text { Via extrafaríngea-lateral } \\
\text { Via retrofaríngea } \\
\text { Via posterior }\end{array}$ \\
\hline Coluna cervical subaxial & $\mathrm{C} 3$ a C7 & $\begin{array}{l}\text { Via retrofaríngea lateral } \\
\text { Via posterior }\end{array}$ \\
\hline Coluna torácica: & $\begin{array}{l}\text { T3 a T4 } \\
\text { T5 a T10 } \\
\text { T1 a T12 }\end{array}$ & $\begin{array}{l}\text { Via transesternal com } \\
\text { complemento cervical } \\
\text { ântero-lateral } \\
\text { Via transesternal ou } \\
\text { toracotomia póstero-lateral* } \\
\text { Toracotomia } \\
\text { Via posterior e póstero-lateral }\end{array}$ \\
\hline Junção toracolombar: & T11 a L1 & $\begin{array}{l}\text { Via retroperitoneal combinada } \\
\text { com toracotomia } \\
\text { Via póstero-lateral }\end{array}$ \\
\hline Coluna lombar: & $\begin{array}{l}\text { L2 a L4 } \\
\text { L5 a Sacro } \\
\text { L1 a Sacro }\end{array}$ & $\begin{array}{l}\text { Via ântero-lateral retroperitoneal } \\
\text { Via póstero-lateral* } \\
\text { Via póstero-lateral e posterior }\end{array}$ \\
\hline
\end{tabular}

* Recomendada

\section{Métodos de reconstrução e estabilização da coluna vertebral}

Reconstrução do corpo vertebral: a doença metastática envolve geralmente o corpo vertebral e a reconstrução seguida à vertebrectomia é necessária para se obter estabilidade da coluna vertebral ${ }^{18}$, preservar as curvaturas fisiológicas e sustentar a carga axial anterior e a força tensão posterior ${ }^{22}$. Os materiais usados de forma isolada ou associada são: osso autólogo e heterólogo, prótese de metal ou de ligas de carbono e titânio, metilmetacrilato e materiais de cerâmica bioativa ${ }^{26}$.
Doentes com expectativa de sobrevivência superior a seis meses, o enxerto com osso é o preferido, pois é definitivo, fisiológico e a possibilidade de pseudoartrose é diminuída em relação ao uso de outros implantes. Osso autólogo é ideal devido à compatibilidade histológica, porém pode estar comprometido com neoplasia, sendo contra-indicada nessa situação. Osso heterólogo apresenta a possibilidade de não ser incorporado à artrodese devido ao estado imunológico deficiente do doente com câncer ${ }^{24}$. Metilmetacrilato é empregado quando a expectativa de sobrevivência é inferior a seis meses e o doente apresenta condição clínica instável, não permitindo o prolongamento do ato cirúrgico necessário para se obter e adaptar o osso autólogo. Próteses de metal, ligas de carbono ou de titânio e materiais de cerâmica bioativa são indicados em doentes com qualquer período de expectativa de vida ${ }^{36,52}$.

Radioterapia, quando indicada, deve ser iniciada aproximadamente seis semanas após o tratamento cirúrgico, quando o enxerto usado é osso e, uma semana, quando a reconstrução é efetuada com metilmetacrilato $^{39}$.

Exposto no quadro 13, modalidades de reconstrução do corpo vertebral na doença metastática relacionada com a expectativa de sobrevivência.

\begin{tabular}{|c|c|}
\hline \multicolumn{2}{|c|}{$\begin{array}{c}\text { Quadro } 13 \\
\text { Reconstrução do corpo vertebral e expectativa de sobrevivência }\end{array}$} \\
\hline Osso autólogo & Sobrevivência superior a seis meses \\
\hline Metilmetacrilato & Sobrevivência inferior a seis meses \\
\hline Implantes & Qualquer expectativa de sobrevivência \\
\hline
\end{tabular}

Estabilização da coluna vertebral: o equilíbrio entre as forças fisiológicas de distração da coluna anterior e de compressão da coluna posterior são os objetivos, e a escolha do sistema de fixação externa do corpo vertebral depende do segmento da coluna vertebral a ser fixada ${ }^{22}$. Os sistemas de fixação incluem hastes, placas de contenção, ganchos e parafusos ou associações destes instrumentos ${ }^{26}$.

- Estabilização anterior: o uso de implante interno ou de osso na reconstrução do corpo vertebral deve ser acompanhado de um sistema de fixação externo em um nível vertebral cranial e caudal em relação à vertebrectomia efetuada ${ }^{18}$. Corpectomia vertebral de dois a três níveis necessita de sistemas de estabilizações via posterior, apesar da reconstrução anterior das vértebras. A depender da expectativa de sobrevivência do doente e da aptidão clínica para suportar dois procedimentos cirúrgicos, um procedimento cirúrgico único é mais razoável, empregando a via póstero-lateral ${ }^{20}$. 
- As integridades ósseas dos corpos vertebrais adjacentes à corpectomia devem ser suficientes para a adaptação e fixação do sistema de implante; caso contrário, um sistema de fixação posterior deve ser indicado ${ }^{20}$.

- Estabilização posterior: a estabilidade da coluna torácica é auxiliada através do gradil costal, porém a destruição neoplásica e a retirada cirúrgica dos pedículos na abordagem e tratamento do tumor tendem a deformar e produzir cifose nesse segmento da coluna vertebral. A presença de cifose implica em incompetência dos ligamentos da coluna vertebral e ocorre a evolução da deformidade com o aumento da cifose, apesar da reconstrução e fixação do corpo vertebral. Esse fato ocorre especialmente na junção toracolombar em decorrência da orientação das facetas torácicas apresentarem orientação mais sagital do que as facetas lombares e a presença do aumento da força biomecânica entre o segmento torácico, relativamente rígido, em relação à maior mobilidade do segmento lombar. Estabilização suplementar posterior deve acompanhar a reconstrução anterior. Indicado também quando duas ou mais vértebras, contíguas ou não, são reconstruídas anteriormente, mesmo com placas de contenção ${ }^{18,20}$. Quando efetuada a laminectomia, dois níveis segmentares vertebrais nos sentidos cranial e caudal devem ser fixados ${ }^{13,23,51}$.

Vertebroplastia percutânea: procedimento minimamente invasivo, indicado nos doentes com dor axial na coluna vertebral, candidatos ao tratamento não cirúrgico (devido à expectativa de sobrevivência reduzida) e doença em múltiplos níveis. As contraindicações incluem: compressão epidural secundária a presença da metástase e fragmentos ósseos do muro posterior do corpo da vértebra no interior do canal vertebral; impossibilidade da localização da(s) vértebra(s) responsável(s) pelos sintomas da dor; intolerância à posição do decúbito para ser realizado o procedimento; coagulopatia; infecção no local da punção percutânea. A vertebroplastia consiste na injeção de metilmetacrilato para o interior do corpo vertebral fraturado secundário à metástase. A diferença da técnica da cifoplastia é a prévia dilatação óssea interna no local do colapso do corpo vertebral com balão apropriado. Após ser tirado o balão, o espaço é preenchido com metilmetacrilato, restaurando a altura do corpo vertebral. A radioscopia dirige a orientação do procedimento.

$\mathrm{O}$ índice de complicações em ambos procedimentos é inferior a $10 \%$ e inclui: extravasamento do metilmetacrilato para o interior do canal vertebral resultando em compressão secundária dos nervos espinhais e medula espinhal; absorção venosa do cimento com embolia pulmonar (minimizado com venografia e embolizações

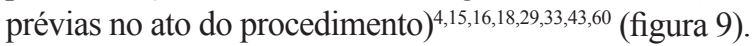

\section{Conclusões}

1. Método científico: as recomendações das diretrizes devem ser seguidas para obter eficácia e eficiência no tratamento. Não há padrão da prática médica.

2. Prognóstico: os fatores preditivos de sobrevivência indicam o prognóstico e auxiliam a escolha da modalidade de tratamento.

3. Diagnóstico: as imagens da ressonância magnética contribuem para o estadiamento da doença metastática na coluna vertebral e a escolha da

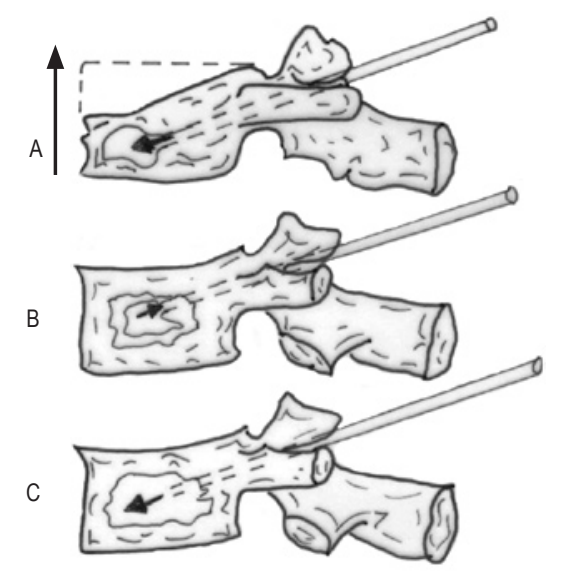

Figura 9 - Vertebroplastia e cifoplastia. O corpo vertebral em colapso é acessado via transpedicular. Na cifoplastia, é inflado o balão em situação distal ao instrumento de punção (agulha apropriada), restaurando a altura da vértebra (A). Na vertebroplastia, não é usado o balão. $O$ balão é retirado e o defeito preenchido com o cimento ósseo (metilmetacrilato), estabelecendo a integridade do corpo vertebral (B e C). 
modalidade do tratamento. As imagens ósseas da tomografia axial computadorizada auxiliam nas táticas e técnicas cirúrgicas de estabilização da coluna vertebral e da reconstrução do(s) corpo(s) vertebral(is).

4. Tratamento: medicamentos como esteróides são recomendados. Os objetivos do tratamento cirúrgico incluem a descompressão circunferencial da medula espinhal, a reconstrução do corpo vertebral e a estabilização segmentar da coluna.

\section{Adendo}

Os desenhos foram elaborados pelo autor e, quando designado, modificado em relação à publicação original.

\section{Agradecimentos}

Aos profissionais da área de pesquisa da Biblioteca da Faculdade de Ciências Médicas da Santa Casa de São Paulo na assessoria da busca e aquisição das referências bibliográficas.

\section{Referências}

1. ABDI S, ADAMS CI, FOWERAKER, O'CONNORA: Metastatic spinal cord syndromes: imaging appearances and treatment planning. Clin Radiol 60:637-47, 2005.

2 ABRAHAM JL: Assessment and treatment of patients with malignant spinal cord compression. Supp Oncol 2:377-401, 2004.

3 AKEYSON EW, McCUTCHEON IE: Single-staged posterior vertebrectomy and replacement combined with posterior instrumentation for spinal metastases. J Neurosurg 85:21120, 1996.

4 AMAR AP, LARSEN DW, ESNAASHARI N, ALBUQUERQUE FC, LAVINE SD, TEITELBAUM GP: Percutaneous transpedicular polymethylmethacrylate vertebroplasty for the treatment of spinal compression fractures. Neurosurgery 49:1105-15, 2001

5 AMERICAN SPINAL INJURY ASSOCIATION: Standards for neurological classification of spinal injury patientes. Chicago, IL. ASIA, 1989.

6 BARCENA A, LOBATO RD, RIVAS JJ, CORDOBES F, CASTRO S, CABRERA A, LAMAS E: Spinal metastatic disease: analysis of factors determining functional prognosis and the choice of treatment. Neurosurgery 15:820-27, 1984.

7 BIGOS S, BOYER O, BRAEN G: Acute low back problems in adults: assessment and treatment. Clinical practice guide- line. Quick reference guide for clinicians (14). US Department of Health and Human Services Public Health Service. Agency for Health Care Policy and Research, AHCPR. Pub. 95-0643, December, 1994.

8 BORIANI S, BIAGINI R, De LURE F, BERTONI F, MALAGUTI M, Di FIORE M, ZANONI A: En bloc resections of bone tumors of the thoracolumbar spine: a preliminary report on 29 patients. Spine 21:1927-31, 1996.

9 BRYNE TN: Spinal cord compression from epidural metastases. New Eng J Med 327:614-19, 1992.

10 BÜNGER C, LAURSEN, HANSEN ES, NEUMANN P, CHRISTENSEN FB, HOY K, HELMIG P: A new algorithm for the surgical treatment of spinal metastases. Current Opinion in Orthopedics 10:101-5, 1999.

11 CAHILL DW, KUMAR R: Palliative subtotal vertebrectomy with anterior and posterior reconstruction via a single posterior approach. J Neurosurg (Spine 1) 90:27-34, 1999.

12 CASPAR W, PITZEN T, PAPAVERO L, JOHNSON TA: Anterior cervical plating for the treatment of neoplasms in the cervical vertebrae. J Neurosurg (Spine 1) 90:27-34, 1999.

13 COOPER P, ERRICO TJ, MARTIN R, CRAWFORD B, Di BARTOLO T: A systematic approach to spinal reconstruction after anterior decompression for neoplastic disease of the thoracic and lumbar spine. Neurosurgery 32:1-8, 1993.

14 DENIS F: The three column spine and its significance in the classification of acute thoracolumbar spinal injuries. Spine 8:817-31, 1983.

15 ECKER R, ENDO T, WETJEN N, KRAUSS W: Diagnosis and treatment of vertebral column metastases. Mayo Clin Proc 80:1177-86, 2005.

16 FINKELSTEIN JA, YEE A: Management of metastatic disease to the spine. Techn Orthop 19:30-7, 2004.

17 FOURNEY DR, ABI-SAID D, RHINES LD, WALSH GL, LANG FF, McCUTCHEON IE, GOKASLAN ZL: Simultaneous anterior-posterior approach to the thoracic and lumbar spine for the radical resection of tumors followed by reconstruction and stabilization. J Neurosurg (Spine 2) 94:232-44, 2001.

18 FOURNEY DR, GOKASLAN ZL: Thoracolumbar spine: surgical treatment of metastatic disease. Curr Op Orthop 14:144-52, 2003

19 FOURNEY DR, GOKASLAN ZL: Spinal instability and deformity due to neoplastic conditions. Neurosurg Focus 14:1-7, 2003

20 FOURNEY DR, GOKASLAN ZL: Use of "MAPS" for determining the optimal surgical approach to metastatic disease of the thoarcolumbar spine: anterior, posterior, or combined. J Neurosurg (Spine 2) 95:40-9, 2005.

21 HADLEY MN, WALTERS BC, GRABB PA, OYESIKU NM, PRZYBYLSKI GJ, RESNICK DK, RYKEN TC, MIELKE DH: Guidelines for the management of acute cervical spine and spinal cord injuries. Neurosurgery 50(3 S):S407-98, 2002.

22 HARMS J, TABASSO G: Técnica cirúrgica para tumor metastático. In Harms J, Tabasso G (ed): Instrumentação em cirurgia da coluna vertebral. Rio de Janeiro, Ed Port, Di-Livros, 2001, cap 4, pp 95-128.

23 HARRINGTON KD: Metastatic disease of the spine. J Bone Joint Surg 68A:1110-15, 1986.

24 HEALEY JH, BROWN HK: Complications of bone metastases. Cancer Suppl 88:2940-51, 2000.

25 HIRABAYASHI H, EBARA S, KINOSHITA, YUZAMA Y, NAKAMURAI, TAKAYASHI J, KAMIMURAM, OHTSUKAK, TAKAOKA K: Clinical outcome and survival after palliative surgery for spinal metastases. Cancer 97:476-84, 2003.

26 KALFAS IA: Anterior thoracolumbar stabilization. Neurosurg Clin N Am 8:487-98, 1997. 

LR, BORSTLAP ACW, TIJSSEN CC, BOSH A, TIJSSEN JGP: Prediction of spinal epidural metastases. Arch Neurol 57:690-5, 2000

28 KILMO P, KESTLE JRW, SCHMIDT MH: Treatment of metastatic spinal epidural disease: a review of the literature. Neurosurg Focus 15:1-9, 2003.

29 KILMO P, SCHMIDT MH: Surgical management of spinal metastases. Oncologist 9:188-96, 2004.

30 KILMO P, THOMPSON CJ, KESTLE JRW, SCHMIDT MH: A meta-analysis of surgery versus conventional radiotherapy for the treatment of metastatic spinal epidural disease. Neuro-Oncol 7:64-76, 2005.

31 KOSTUIK JP, ERRICO TJ, GLEASON TF, ERRICO CC: Spinal stabilization of vertebral column tumors. Spine 13:250-6, 1988.

32 LEVACK P, GRAHAM J, COLLIE D, GRANT R, KIDD J, KUNKLER I, GIBSONA, HURMAN D, MCMILLAN N, RAMPLING R, SLIDER L, STATHAM P, SUMMERS D: Don't wait for sensory level-listen to the symptoms: a prospective audit of the delays in diagnosis of malignant cord compression. Clin Oncol 14:472-80, 2002.

33 LIEBERMAN I, REINHARDT MK: Vertebroplasty and Kyphoplasty for osteolytic vertebral collapse. Clinical Orthop Rel Res 415S:S176-86, 2003.

34 Van der LINDEN YM, DIJKSTRA SP, VONK EJ, MARIJNEN CA, LEER JW: Prediction of survival in patientes with metastases in the spinal column. Cancer 15:320-8, 2005.

35 LOBLAW DA, PERRY J, CHAMBERS A, LAPERRIERE $\mathrm{NJ}$ : Systematic review of the diagnosis and management of malignant extrdural spinal cord compression: the cancer care Ontario practice guidelines initiative's neuro-oncology disease site group. J Clin Oncol 23:2028-37, 2005.

36 MANABE S, TATEISHI A, ABE M, OHNO T: Surgical treatment of metastatic tumors of the spine. Spine 14:41-7, 1989

37 MEDEIROS LR, STEIN A: Níveis de evidência e graus de recomendação da medicina baseada em evidências. Revista AMRIGS 46:43-6, 2002.

38 MENEZES AH: Ventral exposures of the upper cervical spine. In: Benzel EC (ed) Surgical exposure of the spine: an extensile approach. Park Ridge, IL, American Associaton of Neurological Surgeons, 1995, pp 39-53.

39 MUT M, SCHIFF D, SHAFFREY ME: Metastases to nervous system: spinal epidural and intramedullary metastases. J Neuro-Oncol 75:43-56, 2005

40 NORTH RB, LaROCA VT, SCHWARTZ J, NORTH CA, ZAHURAK M, DAVIS RF, McAFEE PC: Surgical management of spinal metastases: analysis of prognostic factors during a 10year experience. J Neurosurg (Spine 2) 97:564-73, 2005.

41 PATCHELL R, TIBBS PA, REGINE WF, PAYNE R, SARIS S, KRYSCIO RJ, MOHIUDDIN M, YOUNG B: Direct decompressive surgical resection in the treatment of spinal cord compression caused by metastatic cancer: a randomised trial. Lancet 366:643-48, 2005.

42 PRABHU VC, BILSKY MH, JAMBHEKAR K, PANAGEAS KS, BOLAND PJ, LIS E, HEIER L, NELSON PK: Results of preoperative embolization for metastatic spinal neoplasms. J Neurosurg (Spine 2) 98:156-64, 2003.

43 RATLIFF JK, COOPER PR: Metastatic spine tumors. South Med Ass 97:246-53, 2004.

44 RYKEN TC, EICHHOLZ KM, GERSZTEN PC, WELCH WC, GOKASLAN ZL, RESNICK DK: Evidence-based review of the surgical management of vertebral column metastatic disease. Neurosurg Focus 15:11, 2003.

45 SCHICK U, MARQUARDT G: Pediatric spinal tumors. Pediatr Neurosurg 35:120-7, 2001.

46 SEOL HJ, CHUNG CK, KIM HJ: Surgical approach to anterior compression in the upper thoracic spine. J Neurosurg (Spine 3) 97:337-42, 2002.

47 SIEGAL T, SIEGAL T: Surgical decompression of anterior and posterior malignant epidural tumors compressing the spinal cord: a prospective study. Neurosurgery 17:424-32, 1985.

48 SIEGAL T, SIEGAL T: Current considerations in the management of neoplastic spinal cord compression. Spine 14:223-8, 1989.

49 SIOUTOS PJ, ARBIT E, MESHULAM CF, GALICICH JH: Spinal metastases from solid tumors. Cancer 76:1453-9, 1995.

50 SUNDARESAN N, STEINBERGER AA, MOORE F, SACHDEV VP, KROL G, HOUGH L, KELLIHER K: Indications and results of combined anterio-posterior approaches for spine tumor surgery. J Neurosurg 85:438-46, 1996.

51 SUNDARESAN N, KROL G, STEINBERGER AA, MOORE $F$ : Management of tumors of the thoracolumbar spine. Neurosurg Clin N Am 8:541-52, 1997.

52 SUNDARESAN N, ROTHMAN A, MANHART K, KELLIHER K: Surgery for solitary metastases of the spine: rationale and results of treatment. Spine 27:1802-6, 2002.

53 SUNDARESAN N, BORIANI S, ROTHMAN A, HOLZMAN R: Tumors of the osseous spine. J Neuro Oncol 69:273-90, 2004.

54 TOKUHASHIY, MATSUZAKI H, TORIYAMA S, KAWANO H, OHSAKAS: Scoring system for the preoperative evaluation of metastatic spine tumor prognosis. Spine 15:1110-3, 1990.

55 TOKUHASHI Y, MATSUZAKI H, ODA H, OSHIMA M, RYU $\mathrm{J}$ : A revised scoring system for preoperative evaluation of metastatic spine tumor prognosis. Spine 30:2186-91, 2005.

56 TOMITAK, KAWAHARAN, BABA KH, TSUCHIYAH, NAGATA S, TORIBATAKE Y: Total em bloc spondylectomy for solitary spinal metastases. Internat Orthop 18:291-8, 1994.

57 TOMITA K, KAWAHARA N, KOBAYASHI T, YOSHIDA A, MURAKAMI H, AKAMARU T: Surgical strategy for spinal metastases. Spine 26:298-306, 2001.

58 VENDER JR, HARRISON SJ, McDONNELL DE: Fusion and instrumentation at $\mathrm{C} 1-\mathrm{C} 3$ via the high anterior cervical approach. J Neurosurg (Spine1) 92:24-9, 2000.

59 WALKER MP, YASZEMSKI MJ, KIM CW, TALAC R, CURRIER BL: Metastatic disease of the spine: evaluation and treatment. Clin Orthop Rel Res 415S:S165-S75, 2003.

60 WEILL A, CHURAS J, SIMON JM, SOLA-MARTINEZ T, ENKAOUAE: Spinal metastases: indication for and results of percutaneous injection of acrylic cement. Radiology 199:241-7, 1996

Original recebido em julho de 2006

Aceito para publicação em maio 2007

\section{Endereço para correspondência}

Jefferson Walter Daniel

Rua Tiapira, 264

05574-000 - São Paulo, SP, Brasil

E-mail:dolldani@uol.com.br 